\title{
Zhytska S.A.
}

\section{COMPUTER ASSISTED LANGUAGE LEARNING}

\section{Abstract:}

The article considers the main advantages and disadvantages of computer-assisted language learning, exercises to develop students' communicative competence are suggested. Also the possibilities of the Internet to develop foreign language skills are determined and the necessity to apply modern methods and technologies in the foreign language teaching is highlighted.

Key words: CALL, communicative approach, motivation, foreign language teaching/learning tool.

\section{Аннотация:}

В статье рассматриваются основные преимущества и недостатки использования компьютеров при обучении иностранным языкам, предлагаются упражнения для развития коммуникативной компетенции студентов. Также определень возможности Интернета для развития навыков иноязычного общения и подчеркивается необходимость использования современных методов и технологий в обучении иностранным языкам.

Ключевые слова: изучение языка при помощзи компьютера, коммуникативный подход, мотивация, инструмент обучения/изучения иностранного языка.

\section{Анотація:}

В статті розглядаються основні переваги та недоліки використання комп'ютерів при навчанні іноземним мовам, пропонуються вправи для розвитку комунікативної компетениії студентів. Також визначені можливості Інтернету для розвитку навичок іншомовного спілкування та підкреслюється необхідність використання сучасних методів та технологій у навчанні іноземним мовам.

Ключові слова: вивчення іноземної мови з допомогою комп'ютера, комунікативний підхід, мотивачія, інструмент навчання/вивчення іноземної мови.

In the last few years the number of teachers using Computer-assisted Language Learning (CALL) has increased markedly and numerous articles have been written about the role of technology in education and professional training in the 21 st century. Although the potential of the Internet for educational purposes has not been fully explored yet and the average school still makes limited use of computers, it is obvious that we have entered a new information age in which the links between technology and teaching English as a foreign language (TEFL) have already been established. The objective of the article is to describe the necessity to update methods and techniques of the second language learning and the possibilities of computerassisted language learning in communicative competences development in the technical institutes. It is necessary to understand the huge possibilities of the Internet application in the foreign language learning and teaching to provide wider opportunities for students to communicate effectively with a lot of people around the world in the authentic environment.

Computers have been used for language teaching ever since the 1960's. According to Warschauer \& Healey this 40-year period can be divided into three main stages: behaviorist CALL, communicative CALL, and integrative CALL. Each stage corresponds to a certain level 
of technology and certain pedagogical theories. In the 1960's and 1970's the first form of computer-assisted Language Learning featured repetitive language drills, the so-called drill-andpractice method. It was based on the behaviorist learning model and as such the computer was viewed as little more than a mechanical tutor that never grew tired. It was mainly used for extensive drills, explicit grammar instruction, and translation tests. Communicative CALL emerged in the 1970's and 1980's as a reaction to the behaviorist approach to language learning. Proponents of communicative CALL rejected behaviorist approaches at both the theoretical and pedagogical level. They stressed that CALL should focus more on using forms rather than on the forms themselves. Grammar should be taught implicitly and students should be encouraged to generate original utterances instead of manipulating prefabricated forms. This form of computerbased instruction corresponded to cognitive theories which recognized that learning was a creative process of discovery, expression, and development. The mainframe was replaced by personal computers that allowed greater possibilities for individual work. Popular CALL software in this era included text reconstruction programmers and simulations. The last stage of computer-assisted Language Learning is integrative CALL. Teachers have moved away from a cognitive view of communicative language teaching to a socio-cognitive view that emphasizes real language use in a meaningful, authentic context. Integrative CALL seeks both to integrate the various skills of language learning (listening, speaking, writing, and reading) and to integrate technology more fully into language teaching. To this end the multimedia-networked computer provides a range of informational, communicative, and publishing tools that are potentially available to every student. From the very start, teachers have realized that computers have enormous potential. Studies have consistently shown that students have positive attitudes about computer technology being used in the classroom and that such technology does have a positive impact.

The reasons for using Computer-assisted Language Learning include:

a. experiential learning. The World Wide Web makes it possible for students to tackle a huge amount of human experience. In such a way, they can learn by doing things themselves. They become the creators not just the receivers of knowledge, users develop thinking skills and choose what to explore.

b. motivation. Student motivation is increased, especially whenever a variety of activities are offered, which make them feel more independent.

c. enhance student achievement. Network-based instruction can help pupils strengthen their linguistic skills by positively affecting their learning attitude and by helping them build self-instruction strategies and promote their self-confidence.

d. authentic materials for study. All students can use various resources of authentic reading materials either at school or from their home. Those materials can be accessed 24 hours a day.

e. greater interaction. Random access to Web pages breaks the linear flow of instruction. By sending E-mail and joining newsgroups, EFL students can communicate with people they have never met. They can also interact with their own classmates. Furthermore, some Internet activities give students positive and negative feedback by automatically correcting their on-line exercises. 
f. individualization. Shy or inhibited students can be greatly benefited by individualized, student-centered collaborative learning. High fliers can also realize their full potential without preventing their peers from working at their own pace.

g. independence from a single source of information. Although students can still use their books, they are given the chance to escape from canned knowledge and discover thousands of information sources. As a result, their education fulfills the need for interdisciplinary learning in a multicultural world.

h. global understanding. A foreign language is studied in a cultural context. In a world where the use of the Internet becomes more and more widespread, an English Language teacher's duty is to facilitate students' access to the web and make them feel citizens of a global classroom, practicing communication on a global level.

Language lab equipment allows classes of students to listen to recorded conversations through headphones, equipped with microphones, while a teacher can send instructions, listen into and monitor students through a central control panel. The equipment actually served to separate the students from the teacher and encouraged less motivated students to daydream through the class period. It is likely that a negative experience with language labs has led teachers to be skeptical of new technologies in the classroom. The more drill practice the students encountered, the faster they would learn the second language. While the language laboratory was a positive step in linking technology and language education, it was soon recognized that such activities were both tedious and boring for learners. Furthermore, the amount of student-teacher interaction was minimal, and individualized instruction was irrelevant. Besides the pedagogical deficiencies, the audio equipment was cumbersome and prone to breakdown, and had only one function-to disseminate auditory input. These factors put together led to a shift to the communicative approach to second language education, namely, computer assisted language learning.

The barriers inhibiting the practice of Computer-assisted Language Learning can be classified in the following common categories:

a. financial barriers. They include the cost of hardware, software, maintenance, and extend to some staff development. Computer-assisted Learning costs the same as conventional instruction but ends up with producing higher achievement in the same amount of instructional time; it results in students achieving the same level but in less time.

b. availability of computer hardware and software. It is the most pressing challenge in applying the new technologies in education. There are few educators skilled in designing it because software development is costly and time-consuming. Computer hardware and software compatibility goes on to be a significant problem. Choosing hardware is difficult because of the many choices of systems to be used in delivering education, the delivery of equipment, and the rapid changes in technology.

c. technical and theoretical knowledge. Not only there is a shortage of knowledge about developing software to promote learning but many instructors do not understand how to use the new technologies. Furthermore, little is known about integrating these new means of learning into an overall plan. Improper use of technologies can affect both the teacher and learner negatively. 
d. acceptance of the technology. Wrong conceptions about the use of technology limit innovation and threaten teachers' job and security. Instructors tend not to use technologies that require substantially more preparation time, and it is tough to provide instructors and learners access to technologies that are easy to use. The World Wide Web makes it possible for students to tackle a huge amount of human experience. In such a way, they can learn by doing things themselves. They become the creators not just the receivers of knowledge, users develop thinking skills and choose what to explore.

Microcomputers and quality CALL software provided yet another medium for language learning. Their potential as both a teaching and learning tool are widely written about in the educational literature. At present, there are a variety of computer applications available including vocabulary, grammar, and pronunciation tutors, spell checkers, electronic workbooks, writing and reading programs, as well as various authoring packages to allow instructors to create their own exercises to supplement existing language courses. In addition to the range of software available, CALL has also been shown to increase learner motivation. Chun and Brandl also suggest that the interactive and multimedia capabilities of the computer make it an attractive teaching/learning tool. Computers can provide immediate feedback to students and students can work at an individualized pace. Software can be designed to include sound, graphics, video, and animation. Moreover, information is presented in a non-linear sequence enabling learners to select the exercises or concepts they wish to review. Despite the advantages and widespread use of CALL, it continues to suffer from criticisms for several reasons. Many believe that learning and practicing grammar rules of a foreign language through fill-in-the-blank exercises, for example, does little to improve a speaker's ability to produce grammatically appropriate utterances. Others point out that CALL suffers from its rigidity in light of the complexities of natural languages. Computer programs designed to provide drill practice are useful for only that and nothing else. Recently, however, we are beginning to see encouraging and promising results in the area of CALL software development. Interactive video and programs which provide more authentic and communicative task-based activities are being created, which are more in line with the current theoretical and pedagogical views of learning. While the computer is now used in some form or another in most language classrooms, and is considered standard equipment, the Internet is also gradually being introduced in the second language classroom as teachers become more familiar with it. When thinking or writing about electronic materials it helps to distinguish between CALL materials (i.e. ELT materials available from websites, computer software, courseware and online courses), web sources of language experience (e.g. Google, YouTube, Facebook) and ICT applications which can be made use of both to deliver materials and to facilitate interaction (e.g. mobile phones). It is worth keeping these distinctions in mind when considering the potential benefits of electronic materials put forward below:

- facilitating reading by making hidden information available, by providing on-the-spot help, by supporting comprehension with graphics, video and sound, and facilitating writing through modeling the genre, demonstrating the process, facilitating brainstorming and research, helping to draft and providing the potential for conferencing, editing and revision;

- organisational advantages such as easy access, convenient storage and retrieval, easy sharing and recycling and cost efficiency; pedagogical advantages such as authenticity, interaction and situated learning; learner advantages such as instant feedback, choice of route and sequence, monitoring of progress, control and empowerment; 
- localised adaptation of materials; free source of a variety of authentic texts; out-of-class opportunities for spoken interaction between learners; development of digital literacy through comparing and evaluating sources of similar information; choice of routes and activities when using teacher blog materials;

- collaborative problem solving activities inside and outside the classroom; interaction in simulated environments such as Second Life; modeling and feedback for pronunciation practice; resources for intensive and extensive listening (and viewing) at the learner's convenience; opportunities for integrated learning environments.

Over the past few years, the Internet has emerged as a prominent new technology. The influence of such a powerful technological tool has pervaded all aspects of the educational, business, and economic sectors of our world. The Internet is the latest in a series of technological innovations for second language education. In order to understand the role of the Internet, it would be useful to provide a brief history of technology and language teaching, present a survey of the technological resources available to second language learners, and, finally consider the role of the Internet and its possibilities. There is a wide range of on-line applications which are already available for use in the foreign language class. These include dictionaries and encyclopedias, links for teachers, chat-rooms, pronunciation tutors, grammar and vocabulary quizzes, games and puzzles, literary extracts. The World Wide Web (WWW) is a virtual library of information that can be accessed by any user around the clock. If someone wants to read or listen to the news, for example, there are a number of sources offering the latest news either printed or recorded. The most important newspapers and magazines in the world are available on-line and the same is the case with radio and TV channels. Another network-based EFL activity could be project writing. By working for a project a student can construct knowledge rather than only receive it. Students can work on their own, in groups of two or in larger teams, in order to write an assignment, the size of which may vary according to the objectives set by the instructor. A variety of sources can be used besides the Internet. The Internet itself can provide a lot of food for thought. The final outcome of their research can be typed using a word processor.

The development of the Internet brought about a revolution in the teachers' perspective, as the teaching tools offered through the Internet were gradually becoming more reliable. Nowadays, the Internet is gaining immense popularity in foreign language teaching and more and more educators and learners are embracing it. The Internet and the rise of computermediated communication in particular have reshaped the uses of computers for language learning. Students will need to learn how to deal with large amounts of information and have to be able to communicate across languages and cultures. At the same time, the role of the teacher has changed as well. Teachers are not the only source of information any more, but act as facilitators so that students can actively interpret and organize the information they are given, fitting it into prior knowledge. Students have become active participants in learning and are encouraged to be explorers and creators of language rather than passive recipients of it [1]. Integrative CALL stresses these issues and additionally lets learners of a language communicate inexpensively with other learners or native speakers. As such, it combines information processing, communication, use of authentic language, and learner autonomy, all of which are of major importance in current language learning theories.

The Internet is a confederation of thousands of computers from various sectors of society such as education, business, government and the military. Each individual system brings 
something different to the whole (databases, library services, graphs, maps, electronic journals, etc), and the end result is a vast accumulation of information. It can be used to both exchange information through electronic mail, newsgroups, list serves, professional on-line discussion groups, and so forth, as well as to retrieve information on a variety of topics through the World Wide Web. Although the Internet has been available to most people, only recently have educators been realizing the potential the Internet can have in second and foreign language classrooms. The following section will therefore consider some of these potential benefits and advantages of incorporating such technology in language courses. The Internet has been used by some language instructors in creative ways - one of these innovations being use of electronic mail. Overall, e-mail can encourage students to use computers in realistic, authentic situations in order to develop communicative and thinking skills. Writing on e-mail can therefore be used to generate ideas about a topic, or can enable learners to free-write without any impositions. E-mail can also be used in various conference-type formats or to generate discussion. Students read entries and then respond to them via e-mail. This allows each student to express their opinion. In this manner, all opinions are voiced and heard, something which may not always occur in oral discussions in the classroom. Chat rooms can also be carried out through e-mail. In this situation, two or more individuals can "talk" on-line about various topics or issues. For instance, language learners can be paired up and can be given a debatable topic to discuss. Such experiences once again stimulate authentic communication and assist students in developing specific communication skills such as arguing, persuading, or defending a particular point. List serves from around the world can offer news and discussion groups in the target language providing another source of authentic input and interaction. In addition to the communication benefits of the Internet, it can also be used to retrieve and access information. The World Wide Web is therefore a virtual library at one's fingertips; it is a readily available world of information for the language learner. While the Internet offers numerous benefits to the language learner, a few such possibilities are examined here, in the context of language learning. Perhaps one of the most essential pedagogical principles of language teaching is one that emphasizes the study of language in a cultural context. Understanding the culture of the target language enhances understanding of the language. The Internet is a valuable resource to both language teachers and learners. As discussed previously, e-mail on the Internet allows language learners to communicate with native speakers. In this manner, the Internet facilitates the use of the specific language in an authentic setting. The Internet can also be used to acquire information from language resources for a variety of purposes. For example, students can access current information from countries around the world. They can obtain geographical, historical, social/cultural, economic, and political information from the countries in which the target language is spoken. Students can read web versions of daily newspapers and same-day news reports. Such experiences can allow learners to participate in the culture of the target language, which in turn can enable them to further learn how cultural background influences one's view of the world. The Internet also serves as a medium for experiencing and presenting creative works. While students can peruse the information on the Net, they can also use it as a platform for their own work such as essays, investigations, or stories.

As Mike describes, the use of the Internet has also been shown to promote higher order thinking skills. A language teacher, for example, may instruct learners to search for specific information. Searching the Web requires logic skills. Once information has been obtained, the results must be reviewed which requires scanning, discarding, and evaluative judgment on part 
of the learner. The information must be put together to make a complete and coherent whole which entails the synthesis process. Such an endeavor permits students to practice reading skills and strategies. In addition to being a supplement to reading materials, especially current information, when students are exploring the Net, they are essentially exploring the real world. Such browsing or exploration can also lead to incidental learning as they encounter a variety of information in this way. Communication with native speakers furthers literacy development for authentic purposes, enables language learners to compare student perspectives on an issue, and allows them to practice specific skills such as negotiating, persuading, clarifying meaning, requesting information, and engaging in true-life, authentic discussion. Promotion of literacy also occurs within a social context. The interaction that results from the above situations can lead to cooperative projects and increased communication between students from all over the world, in turn leading to the development of social skills. Finally, use of the Internet can promote computer skills and the technical and conceptual experiences of using a computer. Lastly, the Internet provides supplemental language activities which can provide students with additional practice in specific areas of language learning. These include reading tests and comprehension questions, grammar exercises, pronunciation exercises possible through the available multimedia capabilities, cloze tests, vocabulary exercises, and so forth. Students can search the Web for such sites, or teachers may recommend specific sites on the Web. Published lists are also available from various sources for both language teachers and language learners, some of which relate to issues of language learning, others which use language as a medium for discussion of culture or current affairs, and others which assist in locating native speakers.

Because the use of the Internet is widespread in numerous fields and domains, without doubt, it also carries great potential for educational use, especially for second and foreign language education. We have described some of the potential benefits of the Internet and how it can be used in the second or foreign language classroom. However, such a discussion would be incomplete without addressing the disadvantages or obstacles related to the use of the Internet in the language classroom. While the Internet and its various facets offer a great deal to the language learner, it is not without problems. The nature of the Internet itself can be a disadvantage at times. When lines are busy due to many users, it may take time to access information or browse the Net and technical glitches themselves can lead to frustration. Lack of training and familiarity on part of the teachers can make it difficult to implement the Internet in the language classroom. Foreign language teachers are especially anxious about prone to computers since they often have little experience with computers. For the most part, computers are used for business or computer science courses. Costs related to training, as well as on-line costs of using a provider are issues that may interfere with implementing such a technology in higher schools, especially in those which have little funding. Censorship may also be a concern to language programs and instructors. The Internet offers access to all types of issues and topics, some of which are unsuitable for children, and this in itself may result in various problems. While some precautions can be taken at the present time, they are not full proof by any means. Although electronic, the Internet is an entity related to literacy - people still interact with it entirely through reading and writing. For this reason alone, the Internet is a technology that will, without doubt, have significant implications for both teaching and learning. Teachers must become familiar with using the Internet and its various functions such as e-mail. They must also learn how to use specific search tools in order to access information, search for lesson plans, or 
material and ideas to supplement their lessons. Lastly, language teachers must learn now to transfer files from Internet sites to their own computer and vice versa. Obtaining information or literature on the Internet, either through the Net itself, through books, or by attending workshops and courses will further assist this process. The more enthusiastic and more knowledgeable language teachers are, the more successfully they can implement Internet in the language classroom. For the language learner, the Internet offers a world of information available to students at the touch of a button. While it must be recognized that the Internet cannot replace the language classroom or the interaction between the language teacher and student, if offers a vast amount of information and lends it to communication possibilities that can greatly enhance the language learning experience. Developing academic literacy is especially difficult for ESL students who are struggling to acquire and improve the language and critical thinking skills they need to become full members of the college mainstream community. The needs of these ESL students may be met through the creation of a functional language learning environment that engages them in meaningful and authentic language processing through planned, purposeful, and academically-based activities, teaching them how to extract, question, and evaluate the central points and methodology of a range of material, and construct responses using the conventions of academic writing [4]. Effective academic writing requires from the student to be able to choose appropriate patterns of discourse, which in turn involves knowing sociolinguistic conventions relating to audience and purpose. These skills, acquired through students' attempts to process and produce texts, can be refined over time by having students complete a range of assignments of progressive complexity which derive from the sustained and focused study of one or more academic disciplines. Through its extensive collection of reading materials and numerous contexts for meaningful written communication and analysis of issues, the Internet creates a highly motivating learning environment that encourages ESL students to interact with language in new and varied ways. Used as a resource for focus discipline research, the Internet is highly effective in helping these students develop and refine the academic literacy so necessary for a successful studying experience. Used as a tool for sustained content study, the Internet is a powerful resource that offers easier, wider, and more rapid access to interdisciplinary information than traditional libraries do. Using the Internet allows students to control the direction of their reading and research, teaches them to think creatively, and increases motivation for learning as students work individually and collaboratively to gather focus discipline information. By allowing easy access to cross-referenced documents and screens, Internet hypertext encourages students to read widely on interdisciplinary topics. This type of reading presents cognitively demanding language, a wide range of linguistic forms and enables students to build a wider range of schemata and a broader base of knowledge, which may help them grasp future texts. Students need the research skills to complete focus discipline projects. Moreover, the research skills acquired through sustained content study and focus discipline research enable students to manage information more effectively, which serves them throughout their college years and into the workforce. The Internet search activity engages students in linguistic tasks (reading, vocabulary development, and interpretation of language structures) and in research tasks (searching for, accessing, and evaluating information).

Certainly at this point in time, several questions need to be asked to guide future research in this area. How can use of the Internet correspond to the communicative or pedagogical goals of language teaching? How will the Internet and its related facets assist language learners in functioning in the global community? What will the real impact of the Internet in foreign 
language classrooms be? How can the Internet be used more effectively alongside the present language curriculum? While these questions have been examined to some degree, researchers and language educators must further investigate and implement this technology to provide others with guidelines in this area. Without a doubt we are in the center of a "monumental technological paradigm shift, one which will eventually change the way that all instructors teach and the way students learn". While technology should not take over the language classroom, it must be embraced in order to allow educators to do those things which they are unable to do themselves or those which will improve what is currently being done in the classroom. Nowadays it is essential to make informed decisions about how the Internet can be successfully integrated into the language classroom.

Engaging in Computer-assisted Language Learning is a continuing challenge that requires time and commitment. As we live in the 21 st century, we realize that technology as such is not the answer to all our problems. What really matters is how we use technology. We welcome the use of new technologies in language learning, especially for the opportunities this can provide for teachers and learners of flexibility and choice, and for the window on the real world they open up to learners in their classrooms and their homes. We see the mobile phone, in particular, as offering great potential for learners. However, we wary of the misuse of new technologies and wasting money on electronic delivery when there are not enough books; we don't have the resources to ensure reliability. Computers will never substitute teachers but they offer new opportunities for better language practice. They may actually make the process of language learning significantly richer and play a key role in the reform of a country's educational system. The next generation of students will feel a lot more confident with information technology than we do. As a result, they will also be able to use the Internet to communicate more effectively, practice language skills more thoroughly and solve language learning problems more easily.

\section{References:}

1. Brown, I. Internet Treasure Hunts - A Treasure of an Activity for Students Learning English.1999. http://iteslj.org/Lessons/Brown-TreasureHunts.html.

2. Warschauer, M., Turbee, L., \& Roberts, B. Computer learning networks and student empowerment. System, 14(1), 1996, 1-14.

3. Garner, R. \& Gillingham, M. G. Internet Communications in Six Classrooms: Conversations across Time, Space, and Culture. Mahwah, NJ: Lawrence Erlbaum Associates, Publishers. 1996.

4. Pally, M. Critical thinking in ESL: An argument for sustained content. Journal of Second Language Writing, 6(3), 1997, 293-311.

5. Wilkenson, T. W., \& Sherman, T. M. Telecommunications-based distance education: Who's doing what? Educational Technology, 21 (11), 1996, 54-59. 